\title{
JOB SATISFACTION AND IMPORTANCE FOR INTENSIVE CARE UNIT RESEARCH COORDINATORS: RESULTS FROM BINATIONAL SURVEY
}

\begin{abstract}
Objective: To measure Intensive Care Unit Research Coordinator job satisfaction and importance, and to identify priorities for role development.
\end{abstract}

Background: Research Coordinator numbers are growing internationally in response to increasing clinical research activity. In Australia, $1 \%$ of registered nurses work principally in research, many as Research Coordinator. Internationally, the Association of Clinical Research Professionals currently has 6,536 certified Research Coordinator in thirteen countries, with likely additional large numbers practicing without the voluntary certification. RCs are almost always nurses, yet little is know about this emerging specialty.

Design: Cross-sectional study using anonymous self-report questionnaire Methods: After ethics approval, the McCloskey-Mueller Satisfaction Scale and McCloskeyMueller Importance Scale were administered via the internet. The sample were 49 (response rate 71\%) Research Coordinator from the Australia and New Zealand Intensive Care Unit Research Coordinators’ Interest Group.

Results: Research Coordinator were satisfied with structural aspects of the position i.e. working business hours; flexibility of working hours; high levels of responsibility and control over their work. Dissatisfaction was expressed regarding: remuneration and recognition, compensation for weekend work; salary package; career advancement opportunities; and childcare facilities. Conclusions: High priorities for role development are those rated highly important but with much lower satisfaction. These are: compensation for weekend call-out work; salary and remuneration package; recognition by management and clinicians; career advancement 
opportunities; departmental research processes; encouragement and feedback; and number of working hours.

Relevance to clinical practice: Increasing numbers of nurses have been attracted to this clinically based research position. These data contribute to the understanding and development of the role.

\section{KEY WORDS:}

Research personnel

Job satisfaction

Intensive care

Questionnaires

Nurses

Nursing 


\section{INTRODUCTION}

The demand for evidence upon which to base healthcare has never been stronger. Health professionals, policy makers, and the public are increasingly research savvy, and there is a constant stream of new treatments requiring clinical testing. This has resulted in new roles for health professionals who specialise in research, in particular the Research Coordinator (RC).

RCs work within clinical departments such as hospital wards and are responsible for the management of research undertaken in that setting. As such, they specialize in a field of clinical research, such as oncology or cardiology. The role involves various aspects of clinical, academic, administrative and laboratory work. RCs coordinate trials of new medications that require testing for safety and efficacy under strict conditions, as well as departmental research undertaken with the unit doctors, nurses and other health professionals. RC positions are almost always filled by nurses who bring to the research role their skills in patient assessment, education, and advocacy. In addition, nurses bring their ability to coordinate patient care between a myriad of health professionals, hospital departments and other health services. Anecdotal reports describing the position abound with over 70 articles published, the majority since 1990; unfortunately, research into the position is scarce (Roberts \& Rickard 2005).

Within the critical care specialty, anecdotal reports of RCs have emerged from emergency/trauma departments in North America (Jones \& Mitchell-Inwang 2002, Seguin 1990, Unkle et al. 1990) and Australia (Armitage 1997, Waller 2003), a New Zealand coronary care unit (Williams 1999), and Intensive Care Units (ICUs) in the UK (Jones \& Mitchell-Inwang 2002), USA (Anonymous 2003, Knight-Bohnhoff et al. 1995) and South Africa (Steere 1990). The descriptions of the RC role in critical care areas suggest more involvement in departmental projects than in some other specialties where pharmaceutical trials predominate. Critical care RCs seem more likely to 
undertake literature reviews, protocol development, data analysis and presentation/publication of results. (Knight-Bohnhoff et al. 1995, Steere 1990, Unkle et al. 1990, Waller 2003, Williams 1999). The role to mentor other health professionals in research processes and implementation of findings is also emphasized (Jones \& Mitchell-Inwang 2002). Critical care RCs must be experts in the processes for obtaining informed consent with unconscious and/or intubated patients, as well as manage a setting where patients may enter complex research protocols twenty-four hours a day, seven days a week (Jones \& Mitchell-Inwang 2002, Knight-Bohnhoff et al. 1995, Unkle et al. 1990). The role in Australasian intensive care units (ICUs) has never been studied, and only recently described (Roberts \& Rickard 2005).

RC numbers have continued to rise in recent years (Mueller \& Mamo 2000). In Australia, 1\% of registered nurses work in the research field, although the breakdown of RC versus other research positions is unknown (Australian Institute of Health and Welfare 2005). A total of 10,723 RCs from 13 countries have passed the examination to obtain RC certification from the Association of Clinical Research Professionals since 1992 (Association of Clinical Research Professionals 2005). This is in addition to the unknown number of RCs working internationally without certification, which is voluntary, involves a fee and rigorous assessment.

An important issue that is poorly understood is that of job satisfaction for those in the RC role. Only one prior study has specifically examined RC job satisfaction in a survey of mostly North American RCs working on a cardiac trial (Kellen et al. 1994). This study found average job satisfaction to be 3.6 on a 5 point scale $(5=$ a great deal). Items ranked most positively were: autonomy, opportunities to increase knowledge, challenges of doing research, patient contact and continuity. Fewer items were dissatisfactory including: recruitment difficulties, patient deaths, inadequate salary, physician unavailability, and excessive paperwork. A related study 
investigated the RC role compared with a clinical nursing role (Mueller \& Mamo 2002).

Interviews with $24 \mathrm{RCs}$ in North America from a variety of specialties identified both advantages and disadvantages in: relationships with patients and medical researchers, the acquisition of technical/clinical skills and knowledge, and work autonomy/control.

Many anecdotal reports and reviews have raised similar issues regarding the $\mathrm{RC}$ role. The autonomous nature of the position is frequently cited as providing job satisfaction, as well as the frustrations of professional isolation (Ecklund 1999, Waller 2003, Williams 1999). Most authors have promoted positive views regarding the opportunities and satisfaction to be obtained in the RC role (Kenkre \& Foxcroft 2001, Raybuck 1997, Williams 1999). Whilst this is encouraging, there remains an absence of objective data on the $\mathrm{RC}$ role obtained from prospective studies using validated instruments to measure satisfaction. Furthermore, the issue of $\mathrm{RC}$ job satisfaction amongst ICU RCs or for RCs in regions other than North America, has not been previously studied.

The rapid increase in $\mathrm{RC}$ numbers suggests the position is important for clinical research, however, to date these positions have been somewhat 'invisible' and are rarely recognized in professional career paths or industrial awards (Raja-Jones 2002, Roberts \& Rickard 2005, Waller 2003). The UK has recently seen the recognition of research career paths for nurses, including one for RCs (Kenkre \& Foxcroft 2001, Kenkre et al. 2001). In most countries however, RCs exist in a grey area between the health professions, university research awards, and the pharmaceutical industry. The next stage in the development of the position is formal investigations that will provide reliable data. Identification of the level of satisfaction, and the related issues that promote or limit satisfaction will be important to policy-makers, health managers, and RCs themselves as this new role continues to grow within the world of evidence-based healthcare. 


\section{METHODS}

\section{Design}

Cross-sectional study using a self-report questionnaire. This approach was chosen to provide a snapshot of the current situation, and to obtain data from the cohort of interest.

\section{Objectives}

The aims of this study were to:

1. Measure the level of job satisfaction amongst ICU RCs in Australia and New Zealand

2. Measure the importance of a range of job variables to ICU RCs in Australia and New Zealand

3. Develop priorities for role development based on the comparative levels of satisfaction with, and importance of, a range of job variables.

This study was part of a larger survey that also examined demographics, role content, role structure, and perceived positive and negative aspects of the role. These data are reported elsewhere (Rickard et al. 2006, Roberts et al. 2006) submitted).

\section{Study procedures}

Permission was given from the Australia and New Zealand ICU Research Coordinators' Interest Group (IRCIG) for the investigators to distribute the study information on a closed emailing list. Participation was voluntary, anonymous and took approximately 20 minutes to complete on a secure website. Submissions were possible for a two month period in 2004, with completed questionnaires delivered by the computer server over the internet to the researchers. Computer IP addresses were not collected to ensure anonymity. 


\section{Questionnaire}

The previously validated, 31-item McCloskey-Mueller Satisfaction Scale (MMSS) (Mueller \& McCloskey 1990) was distributed. This tool was developed for nurses working in the clinical setting. However, in the absence of an RC-specific job satisfaction instrument, the MMSS was deemed appropriate as most RCs are nurses, and based in the clinical setting. Some MMSS questions were slightly adjusted to be RC specific e.g. 'research processes' for 'delivery of care method', 'medical staff involved in research' for 'physicians you work with'. We also administered what we have named the McCloskey-Mueller Importance Scale (MMIS), an adapted MMSS with identical job items rated for 'importance' rather than 'satisfaction' as suggested by previous users of the MMSS (Ajamieh et al. 1996, Mueller \& McCloskey 1990, Price 2002). Both instruments had minor variations to the wording to be specific to the Australasian context e.g. 'annual leave entitlements' for 'vacation', 'academics' for 'faculty'. Permission to use the MMSS, and clarification about the meaning of various questions were obtained from the developers. Principal components analysis with varimax analysis was performed to assess the underlying dimensions present within the MMIS. Only factors with eigenvalues $>1$ were extracted and only loadings $>0.30$ have been included.

\section{Identification of Priorities for Role Development}

The relative importance and satisfaction scores were compared to allow a richer interpretation of satisfaction data, and to develop priorities for addressing these issues. Issues with low job satisfaction but high importance were considered as the most urgent priority for action. Items ranked low for both satisfaction and importance were interpreted as a second priority, unless easily rectifiable. Items ranked high for both satisfaction and importance were interpreted as a commendation for management and supervisors. 


\section{Ethics}

Ethics Committee approval was obtained prior to circulation of the questionnaire. An explanatory statement attached to the questionnaire clearly stated that participation was voluntary and anonymous.

\section{RESULTS}

\section{Sample}

There were 49 respondents from the mailing-list membership of 69 (response rate $71 \%$ ).

Respondents were predominantly female nurses, with an age of $21-60$ years $(55 \% \leq 40$ years). Most worked in the government sector and all held tertiary qualifications. Over half had additional postgraduate degrees, $12 \%$ had completed and a further $20 \%$ were currently enrolled in a research degree, such as a $\mathrm{PhD}$. Approximately half of all RCs were full-time, and most parttimers worked at least three days per week. Part-time RCs usually (67\%) had additional jobs, usually clinical roles, but also in education, management, quality assurance, or other research positions.

Most (80\%) RCs were the sole RC in their unit. A third had been in the position for four years or more, and another third had undertaken previous research positions. Most RCs were involved with pharmaceutical trials, multi-site trials with the Australia and New Zealand Intensive Care Society Clinical Trials Group, departmental medical and nursing research, and trauma registries/audits. Over one third also initiated their own research projects. Further information on the sample demographics is published elsewhere (Rickard et al. 2006).

The best and worst aspects as perceived by the RCs were described in free text. 'Best' statements from this analysis included: 'building towards the future and endeavouring to produce the best 
care available to the future patients of ICU'. Worst aspects included: 'having to keep an eye on the dollar'. These aspects have been reported elsewhere (Roberts et al. 2006).

\section{Satisfaction}

RCs were generally more satisfied than dissatisfied with the position. The average satisfaction score was 3.84 (SD 1.14), which correlated most closely with the 'moderately satisfied' ranking of the 5 point scale. See Table 1.

$\mathrm{RC}$ satisfaction was higher for those who worked with other RCs (MMSS mean 3.99 vs. 3.80 for solo RCs), and for those who initiated their own research (MMSS mean 3.91 vs. 3.80 for non initiators).

\section{Importance}

The overall mean importance score was 4.27 (SD 0.99), i.e. between moderately and very important. See Table 2. Many (18 of 31) items were rated as moderately or very important by $90 \%$ or more of respondents.

\section{Relationship between satisfaction and importance scores}

The difference between mean satisfaction and importance scores varied from -1.8 to +0.7 . See Table 3. Few items were ranked equally for the importance placed upon them, and satisfaction with that variable. For some items, importance outweighed satisfaction and vice versa. (Table 4).

\section{Validity of MMIS}

Factor analysis identified eleven factors under which the items converged. See Table 5.

Examination of the scree-plot (Figure 1) supported an 11-factor solution, explaining $77.3 \%$ of the variance. These factors were fairly consistently grouped as per those reported previously for the 
MMSS (Mueller \& McCloskey 1990). In addition we have termed the extra three factors as 'Work/Life Balance', 'Control/Conditions', and 'Compensation -Weekends'. Factor coefficients ranged from $0.25-0.94$, with only three of the eleven having a score of $\geq 0.70$. The item 'working with ICU research staff' did not intuitively belong under factor 5 'Extrinsic Rewards' (all other items under this factor relate to salary/package entitlements). However, another correlation factor (of 0.31 ) falls under factor 7 'Research Department', which includes several items in the area of inter-personal work relationships, and seems a better fit. For three items, there was a significant increase in alpha values if these were removed from the analysis. Factors 3, 5 and 6 had coefficients of $0.79,0.64$ and 0.67 if the items 'number of hours worked', 'relationship with other ICU research staff', or 'interaction with other disciplines' were deleted (respectively).

\section{DISCUSSION}

This survey of RCs employed in Australian and New Zealand ICUs found overall high levels of job satisfaction. The average satisfaction score of 3.84 compares favourably with previously reported MMSS scores of 3.27-3.44 in clinical nurses (McCloskey \& McCain 1987). The score is comparable to that of 3.6 obtained using a different 5-point scale in the only previous study of RC job satisfaction (Kellen et al. 1994). When viewed as an average cumulative score, the mean satisfaction was 117.5 from a possible range of $31-155$. The generally good job satisfaction is encouraging and consistent with many positive anecdotal reports.

The most satisfying aspects of the RC position were structural (e.g. hours of work, autonomy) and relationship components (with other professionals and researchers). These items are consistent with those identified by RCs in North American research (Kellen et al. 1994, Mueller \& Mamo 2002). Least satisfying were items reflecting reward and recognition (e.g. salary and promotion opportunities); these issues are a concern. 
RCs ranked most MMIS items as highly important with a mean score of 4.27 out 5 (a mean cumulative score of 132 out of 155). The results indicated a group who place very high importance on most aspects of their job, particularly the level of control over their work and the quality of their workplace relationships.

When using importance data to identify priorities to improve job satisfaction, clear patterns emerged. The most pressing areas of concern were those ranked as highly important, but of low satisfaction. The most concerning problem was that of inadequate remuneration packages, all aspects of which were deemed very unsatisfactory, with the most outstanding issue being inadequate compensation when required to work on weekends. At times of high patient recruitment onto trials, RCs often work overtime, after hours or at weekends to ensure that study requirements are fulfilled. Many are not paid overtime rates or on-call allowances for this additional work and only some are able to take time off in lieu.

Inadequate RC salaries as a source of dissatisfaction was identified a decade ago, but has not been addressed (Kellen et al. 1994). Most RCs have a salary of $\leq$ AUD\$55,000 (approximately $€ 34.100$ ) and one in five $\leq$ AUD $\$ 45,000$ (approximately $€ 27.900$ ). This is considerably lower than RCs could earn if working in a clinical, education or management position. Most RCs are highly qualified and experienced nurses who may seek alternate positions if salary levels are not addressed. The current situation probably reflects a lack of certainty about where RCs 'fit in' to the various health or research career structures. We suggest that starting salaries should be $>/=\$$ AUD 55,000 (approximately $€ 34.100$ ) gross plus superannuation, a mobile phone and possibly a laptop computer. For RCs with more experience, qualifications, or who coordinate larger research departments, higher remuneration on a graduated scale would be appropriate. 
Another key area of concern for RCs is the number of hours worked. When workloads are high, such as when many patients are concurrently enrolled into a trial, RCs often work extra hours but are rarely given extra remuneration. Part-time RCs may desire increased hours; however, as most positions rely on short term funding rather than a dedicated position from the ICU budget, there may be reluctance by budget managers to do so. RC dissatisfaction with excessive hours is no doubt linked to the reported dissatisfaction with compensation for weekend call-outs and the salary package overall.

A crucial area where importance far outweighs satisfaction was that of recognition and career progression. Many RCs believe their work is undervalued by ICU management and clinical staff. This is concerning and surprising; the RC is a key member of the ICU whose work provides evidence for clinical practice and prestige for the unit. Feeling undervalued is likely to be linked to poor wages, ill defined position descriptions, short-term contracts, and a lack of respect from colleagues/managers. In addition, RCs were dissatisfied with opportunities for career advancement. In Australia and New Zealand, as in many countries, RCs have no recognised career structure, either within the health professional (e.g. nursing) or the academic research structures. The UK Royal College of Nursing, in contrast, has well recognised RC pathways from novice to expert, with clearly differentiated appointment and salary levels. (Kenkre \& Foxcroft 2001) Currently RCs are employed on a variety of employment classifications, which differ by country, and State. One solution would be to employ RCs under the National Health and Medical Research Council classifications. This would allow standardisation and improve visibility of the $\mathrm{RC}$ role.

RCs felt overall research processes in their units were not up to the standards that they felt important. Despite reporting high levels of responsibility, control and decision making input, it seems RCs are not able to have as much influence as they would like in order to streamline the 
standard of research processes. This may suggest that while the RC can control the quality of the research projects they directly manage, they are not always able to influence other researchers in the unit. This issue it likely linked to the previously discussed undervaluing of the RC role by ICU managers and clinicians. As the only ICU staff member/s with a dedicated research focus, RCs are the most likely to recognise areas of research process that could be streamlined or improved, and we encourage managers to seek RCs views and support them in implementing change.

On a commendable note for those who employ and manage RCs, many job items that were highly important to RCs also provided high satisfaction. These included the structure of working hours; the Monday to Friday day shift basis combined with flexibility is keenly appreciated by RCs who are predominantly ex-shift workers. The autonomous nature of the position with high control over work, responsibility and decision-making input is highly valued and enjoyed by RCs. Lastly, RCs were strongly committed to and satisfied by their interactions with other health professionals, particularly medical researchers and research staff.

Convenient child care was the only item to achieve both low importance and satisfaction. Although the importance score was influenced by those who did not have children, the low mean satisfaction score did not change when isolated to those $(n=21)$ for whom child care was of moderate or very high importance. Maternity/paternity leave was also of low importance, but of high satisfaction. In Australia, 12 months unpaid maternity leave is standard, and nurses receive 12 weeks paid leave. There was much missing data for both items' satisfaction but almost none for importance. Therefore, mean satisfaction for these items probably reflects those who actually use them, whereas mean importance scores were reduced by the many RCs without young children. Whilst maternity/paternity leave provisions appear adequate, to return successfully to work early, or at all, improvements in childcare facilities are needed. The significant missing 
MMSS data for these questions pose issues in the use of the tool. We did not substitute values for missing data but possibly a score of 3 'neither satisfied nor dissatisfied' should be used. This issue has not been raised by previous MMSS users.

The use of the previously validated MMSS to measure job satisfaction levels was a strength of this study along with an acceptable response rate. However, there were some limitations of this method. The tool was developed for clinical nurses and may not capture all of the concepts inherent to RC satisfaction. Our application of the tool as a web-based questionnaire has not been previously undertaken and, whilst the guaranteed anonymity may have encouraged honest answers, it may have allowed RCs to submit more than one survey. We found no evidence of this and, considering the time required to complete the questionnaire, this seems unlikely. Our sample from the Australian and New Zealand ICU group somewhat limits the generalisability of results to this region and specialty. There is variability between $\mathrm{RC}$ role structures and functions in different institutions, and while we have reported overall satisfaction and importance levels, we did not analyse for the effect that demographic, educational or job-related factors may have on satisfaction. Despite this, most variables had the majority of responses in one direction (positive or negative). Australasian ICUs are on the whole relatively homogenous, being 'closed' (admitting rights only to intensive care specialists), having ICU-only nursing staff, and the binational research community is strong, with a large number of collaborative multi-site trials. The RC satisfaction data presented here provides a benchmark that will allow future comparison with other specialties, nations, and over time.

Inter-item correlations for the MMIS were observed to be grouped in a similar manner to that noted by the developers of the MMSS, although with two more factors (Mueller \& McCloskey 1990). This suggests that the concept of job variable importance is more complex than that of job satisfaction. Some MMIS item loadings were split between $>/=$ two factors at values of $\geq 0.30$, 
although in most cases there was a clearly dominant value. The extra three MMIS factors that emerged in our analysis seemed to correspond to the domains of Safety (Work/Life balance, Compensation-Weekends), and Psychological Rewards (Control/Conditions) as conceptualised in the three factor (Safety/Social/Psychological) nursing rewards/satisfaction model (McCloskey 1974, Mueller \& McCloskey 1990). Three items, when removed, displayed a significant increase in the Cronbach's alpha. These items may be too general to convey a specific concept and, perhaps, should be dropped. Future work should further assess the MMIS, particularly where there is $\geq 2: 1$ ratio of participants to items (Kline 1994). Our ratio was lower; however, it provides the first data supporting validity of the MMIS. The ability to measure both job satisfaction and the perceived importance of job variables is beneficial when interpreting satisfaction scores. We hope that this fills the need for such a tool as identified by previous researchers (Ajamieh et al. 1996, Mueller \& McCloskey 1990, Price 2002).

\section{CONCLUSIONS}

RCs in Australasian ICUs have high overall levels of job satisfaction. It seems the RC role is an attractive position for those looking to specialise in research but remain in the clinical setting. RC numbers have been increasing steadily since the early 1990s and are showing no signs of abating. The specialty has generated many reports in the professional literature but has rarely been subjected to research scrutiny. This study clarifies issues that need to be addressed as this emerging specialty develops. Although RCs enjoy their job, they feel poorly compensated, recognised and perceive a limited career path; these factors are likely to diminish job satisfaction over time, and need to be addressed. Priorities identified in this research as requiring urgent attention are: poor financial remuneration, particularly for weekend call-outs; inadequate professional recognition; lack of career advancement opportunities; excessive working hours; and unsatisfactory departmental research processes. 


\section{Contributions}

Study design: CR, BR, JF, MM

Data collection and analysis: CR, BR, JF, MM

Manuscript preparation: CR, BR, JF, MM 


\section{REFERENCES}

Ajamieh ARA, Misener T, Haddock KS \& Gleaton JU (1996) Job satisfaction correlates among Palestinian nurses in the West Bank. International Journal of Nursing Studies 33, 422432.

Anonymous (2003) The role of a research coordinator. DCCN: Dimensions of Critical Care Nursing 22, 270-271.

Armitage K (1997) Trauma at the new Children's Hospital Westmead NSW: The role of the trauma research nurse. Australian Emergency Nursing Journal 1, 21.

Association of Clinical Research Professionals, Clinical Research Coordinator Certification Guide 2006. Available at: http://www.acrpnet.org/certification/ich/crc/general.html (accessed 20 December 2005)

Australian Institute of Health and Welfare (2005). Nursing and Midwifery Labour Force 2003. Canberra: $1-40$.

Ecklund DJ (1999) Establishing a research coordinator network: The birth of an idea. Journal of Nursing Administration 29, 20-25.

Jones CM \& Mitchell-Inwang C (2002) New roles for nurses in critical care: the research nurse practitioner. Care of the critically ill 18, 110-114.

Kellen JC, Schron EB, McBride R, Hale C, Campion J, Handshaw K, Inkster M \& Ettinger A (1994) A survey of clinical trial coordinators: factors influencing job satisfaction and turnover. Cardiovascular Nursing 30, 25-31.

Kenkre JE \& Foxcroft DR (2001) Career pathways in research: clinical research. Nursing Standard 16, 41-44.

Kenkre JE, Foxcroft DR \& McMahon A (2001) Research career pathways. Nursing Standard 16, 39.

Kline P (1994). An Easy Guide to Factor Analysis. Routledge, London.

Knight-Bohnhoff K, Horne-Lucero L, Kory L \& Fry R (1995) The challenge of trauma clinical trials: facilitation through understanding. Journal of Trauma Nursing 2, 43-49.

McCloskey J (1974) Influence of rewards and incentives on staff nurse turnover rate. Nursing Research 27, 114-120.

McCloskey JC \& McCain BE (1987) Satisfaction, commitment and professionalism of newly employed nurses. Image - The Journal of Nursing Scholarship 19, 20-24.

Mueller CW \& McCloskey JC (1990) Nurses' Job Satisfaction: A proposed measure. Nursing Research 39, 113-117.

Mueller MR \& Mamo L (2000) Changes in medicine, changes in nursing: Career contingencies and the movement of nurses into clinical trial coordination. Sociological Perspectives 43, S43-57.

Mueller MR \& Mamo L (2002) The nurse clinical trial coordinator: benefits and drawbacks of the role. Research and Theory for Nursing Practice 16, 33-42.

Price M (2002) Job satisfaction of registered nurses working in an acute hospital. British Journal of Nursing 11, 275-280.

Raja-Jones H (2002) Role boundaries - research nurse or clinical nurse specialist? A literature review. Journal of Clinical Nursing 11, 415-420.

Raybuck J (1997) The clinical nurse specialist as research coordinator in clinical drug trials. Clinical Nurse Specialist 11, 15-19.

Rickard CM, Roberts BL, Foote J, McGrail MR (2006) Intensive care research coordinators. Who are they and what do they do? Results of binational survey. Dimensions in Critical Care Nursing In press.

Roberts B \& Rickard CM (2005) The role of the intensive care research coordinator in Australia: an invaluable resource for ICU research. Critical Care and Resuscitation 7, 50-52.

Roberts BL, Rickard CM, Foote J, McGrail MR (2006) The best and worst aspects of the ICU 
research coordinator role Nursing in Critical Care 11, 128-(in press).

Seguin DA (1990) My role as research coordinator. Critical Care Nursing Quarterly 12, 39-44.

Steere J (1990) A trialist's perspective of conducting research in ICU. Nursing RSA Verpleging 5, 19-20.

Unkle DW, Talucci RC, Morgan TO \& Schwab CW (1990) Trauma research nurse: a career option. Dimensions of Critical Care Nursing 9, 296-300.

Waller J (2003) An insight into the role of the clinical trials coordinator. Australian Nursing Journal 10, Suppl 1-2.

Williams B (1999) Getting a job as a research nurse. Nursing New Zealand 5, 14-16. 
Table 1. Satisfaction Scores

\begin{tabular}{|c|c|c|c|c|c|}
\hline $\begin{array}{c}\text { Item } \\
\text { No }\end{array}$ & Item & $\mathbf{N}$ & Mean & $\begin{array}{c}\text { Very or } \\
\text { Moderately } \\
\text { Satisfied }\end{array}$ & $\begin{array}{c}\text { Very or } \\
\text { Moderately } \\
\text { Dissatisfied }\end{array}$ \\
\hline 6 & Work normal business hours (non shift-work) & 49 & 4.82 & $94 \%$ & $0 \%$ \\
\hline 5 & Flexibility of your days of work & 49 & 4.49 & $90 \%$ & $4 \%$ \\
\hline 8 & Amount of weekends off per month & 49 & 4.47 & $86 \%$ & $6 \%$ \\
\hline 29 & Level of responsibility & 49 & 4.45 & $90 \%$ & $4 \%$ \\
\hline 22 & Level of control that you have over your work & 49 & 4.37 & $90 \%$ & $8 \%$ \\
\hline 13 & Your immediate supervisor & 49 & 4.27 & $86 \%$ & $6 \%$ \\
\hline 19 & $\begin{array}{l}\text { Opportunities to interact professionally with } \\
\text { disciplines other than your own }\end{array}$ & 49 & 4.20 & $84 \%$ & $4 \%$ \\
\hline 30 & Level of control over your working conditions & 49 & 4.18 & $82 \%$ & $8 \%$ \\
\hline 15 & $\begin{array}{c}\text { ICU medical staff who act as PIs, CIs or Research } \\
\text { Director }\end{array}$ & 49 & 4.10 & $82 \%$ & $8 \%$ \\
\hline 14 & Working with the ICU research staff (other RCs) & 32 & 4.09 & $78 \%$ & $9 \%$ \\
\hline 11 & Option for maternity/paternity leave & 23 & 4.09 & $74 \%$ & $4 \%$ \\
\hline 7 & $\begin{array}{l}\text { Opportunity to work part-time or option to do so } \\
\text { if you so desired }\end{array}$ & 47 & 4.04 & $66 \%$ & $6 \%$ \\
\hline 17 & $\begin{array}{l}\text { Opportunities for social contact with colleagues } \\
\text { at work }\end{array}$ & 49 & 4.02 & $82 \%$ & $8 \%$ \\
\hline 31 & Level of input into decision making & 49 & 3.96 & $73 \%$ & $16 \%$ \\
\hline 9 & $\begin{array}{l}\text { Flexibility of specific weekends off without being } \\
\text { on call }\end{array}$ & 48 & 3.90 & $65 \%$ & $19 \%$ \\
\hline 2 & Annual leave entitlements & 49 & 3.86 & $76 \%$ & $12 \%$ \\
\hline 18 & $\begin{array}{c}\text { Opportunities for social contact with colleagues } \\
\text { outside of work }\end{array}$ & 49 & 3.78 & $57 \%$ & $6 \%$ \\
\hline 21 & Opportunities to belong to ICU committees & 49 & 3.78 & $61 \%$ & $8 \%$ \\
\hline 28 & Opportunities to write and publish journal articles & 48 & 3.67 & $50 \%$ & $10 \%$ \\
\hline 27 & Opportunities to undertake your own research & 49 & 3.65 & $53 \%$ & $16 \%$ \\
\hline 16 & Overall research processes in the unit & 49 & 3.61 & $65 \%$ & $20 \%$ \\
\hline 26 & $\begin{array}{l}\text { Encouragement and positive feedback that you } \\
\text { receive }\end{array}$ & 49 & 3.55 & $55 \%$ & $22 \%$ \\
\hline 4 & Number of hours worked & 49 & 3.51 & $61 \%$ & $27 \%$ \\
\hline 25 & $\begin{array}{l}\text { Recognition of your work by ICU clinical staff } \\
\text { (i.e. doctors, nurses, allied health) }\end{array}$ & 49 & 3.51 & $57 \%$ & $20 \%$ \\
\hline 20 & $\begin{array}{c}\text { Opportunities to interact with university } \\
\text { departments and academics }\end{array}$ & 48 & 3.50 & $44 \%$ & $10 \%$ \\
\hline 24 & Recognition of your work from ICU management & 49 & 3.49 & $59 \%$ & $24 \%$ \\
\hline 23 & Opportunities for career advancement & 48 & 3.25 & $50 \%$ & $33 \%$ \\
\hline 1 & The level of your salary & 49 & 3.16 & $45 \%$ & $31 \%$ \\
\hline 3 & $\begin{array}{c}\text { Other aspects of your remuneration package i.e. } \\
\text { phone/laptop }\end{array}$ & 48 & 2.92 & $40 \%$ & $42 \%$ \\
\hline 12 & $\begin{array}{c}\text { Child care facilities located at or convenient to } \\
\text { your organisation }\end{array}$ & 21 & 2.90 & $38 \%$ & $38 \%$ \\
\hline 10 & Compensation if you have to work on weekends & 34 & 2.88 & $35 \%$ & $50 \%$ \\
\hline
\end{tabular}


Table 2. Importance Scores

\begin{tabular}{|c|c|c|c|c|c|}
\hline $\begin{array}{c}\text { Item } \\
\text { No }\end{array}$ & Item & N & Mean & $\begin{array}{c}\text { Very or } \\
\text { Moderately } \\
\text { Important }\end{array}$ & $\begin{array}{c}\text { Very or } \\
\text { Moderately } \\
\text { Unimportant }\end{array}$ \\
\hline 30 & Level of control over working conditions & 49 & 4.88 & $100 \%$ & $0 \%$ \\
\hline 31 & Level of input into decision making & 49 & 4.84 & $100 \%$ & $0 \%$ \\
\hline 22 & Level of control over work & 48 & 4.83 & $100 \%$ & $0 \%$ \\
\hline 15 & ICU medical staff involved in research & 49 & 4.82 & $96 \%$ & $0 \%$ \\
\hline 16 & Research processes in unit & 49 & 4.78 & $98 \%$ & $0 \%$ \\
\hline 13 & Immediate supervisor & 49 & 4.76 & $100 \%$ & $0 \%$ \\
\hline 10 & Compensation for working weekends & 49 & 4.71 & $94 \%$ & $0 \%$ \\
\hline 29 & Level of responsibility & 48 & 4.71 & $100 \%$ & $0 \%$ \\
\hline 24 & Recognition by ICU management & 49 & 4.69 & $100 \%$ & $0 \%$ \\
\hline 26 & Encouragement \& positive feedback & 48 & 4.65 & $92 \%$ & $0 \%$ \\
\hline 4 & The number of hours worked & 49 & 4.59 & $100 \%$ & $0 \%$ \\
\hline 1 & Salary level & 48 & 4.58 & $100 \%$ & $0 \%$ \\
\hline 5 & Flexibility of days of work & 48 & 4.56 & $90 \%$ & $2 \%$ \\
\hline 25 & Recognition by ICU clinical staff & 49 & 4.55 & $96 \%$ & $2 \%$ \\
\hline 14 & Working with ICU research staff & 49 & 4.49 & $90 \%$ & $2 \%$ \\
\hline 2 & Annual leave entitlements & 48 & 4.48 & $92 \%$ & $0 \%$ \\
\hline 23 & Career advancement opportunities & 49 & 4.45 & $94 \%$ & $2 \%$ \\
\hline 9 & Flexibility of weekends off (without on-call) & 49 & 4.45 & $90 \%$ & $0 \%$ \\
\hline 8 & Number of weekends off per month & 48 & 4.38 & $83 \%$ & $0 \%$ \\
\hline 6 & Work normal business hours (non-shifts) & 48 & 4.38 & $86 \%$ & $4 \%$ \\
\hline 19 & Interaction with other disciplines & 49 & 4.20 & $82 \%$ & $6 \%$ \\
\hline 17 & Social contact with colleagues at work & 49 & 4.00 & $80 \%$ & $6 \%$ \\
\hline 3 & Non-salary aspects of remuneration package & 48 & 3.98 & $75 \%$ & $4 \%$ \\
\hline 27 & Opportunity to undertake own research & 49 & 3.88 & $71 \%$ & $10 \%$ \\
\hline 7 & Having the option to work part-time & 48 & 3.69 & $60 \%$ & $19 \%$ \\
\hline 28 & Writing \& publishing journal articles & 48 & 3.60 & $56 \%$ & $13 \%$ \\
\hline 20 & Interaction with universities \& academics & 49 & 3.47 & $53 \%$ & $20 \%$ \\
\hline 11 & Availability of maternity/paternity leave & 47 & 3.38 & $43 \%$ & $23 \%$ \\
\hline 21 & Membership of departmental committees & 49 & 3.37 & $53 \%$ & $18 \%$ \\
\hline 18 & Social contact with colleagues outside work & 49 & 3.22 & $43 \%$ & $20 \%$ \\
\hline 12 & Convenient childcare facilities available & 49 & 3.08 & $31 \%$ & $27 \%$ \\
\hline & & & & \\
\hline
\end{tabular}


Table 3. Satisfaction scores compared to importance scores

\begin{tabular}{|c|c|c|c|c|}
\hline Number & Item & Satisfaction & Importance & Difference \\
\hline 10 & Compensation for working weekends & 2.9 & 4.7 & -1.8 \\
\hline 1 & Salary level & 3.2 & 4.6 & -1.4 \\
\hline 24 & Recognition by ICU management & 3.5 & 4.7 & -1.2 \\
\hline 23 & Career advancement opportunities & 3.3 & 4.4 & -1.1 \\
\hline 16 & Research processes in unit & 3.6 & 4.8 & -1.2 \\
\hline 26 & Encouragement \& positive feedback & 3.6 & 4.6 & -1.0 \\
\hline 4 & The number of hours worked & 3.5 & 4.6 & -1.1 \\
\hline 3 & $\begin{array}{c}\text { Non-salary aspects of remuneration } \\
\text { package }\end{array}$ & 2.9 & 4.0 & -1.1 \\
\hline 25 & Recognition by ICU clinical staff & 3.5 & 4.6 & -1.1 \\
\hline 31 & Level of input into decision making & 4.0 & 4.8 & -0.8 \\
\hline 15 & ICU medical staff involved in research & 4.1 & 4.8 & -0.7 \\
\hline 30 & $\begin{array}{l}\text { Level of control over working } \\
\text { conditions }\end{array}$ & 4.2 & 4.9 & -0.7 \\
\hline 2 & Annual leave entitlements & 3.9 & 4.5 & -0.6 \\
\hline 9 & $\begin{array}{l}\text { Flexibility of weekends off without on- } \\
\text { call }\end{array}$ & 3.9 & 4.4 & -0.5 \\
\hline 13 & Immediate supervisor & 4.3 & 4.8 & -0.5 \\
\hline 22 & Level of control over work & 4.4 & 4.8 & -0.4 \\
\hline 14 & Working with ICU research staff & 4.1 & 4.5 & -0.4 \\
\hline 29 & Level of responsibility & 4.4 & 4.7 & -0.3 \\
\hline 27 & Opportunity to undertake own research & 3.7 & 3.9 & -0.2 \\
\hline 22 & $\begin{array}{l}\text { Childcare facilities at or convenient to } \\
\text { work }\end{array}$ & 2.9 & 3.1 & -0.2 \\
\hline 5 & Flexibility of days of work & 4.5 & 4.6 & -0.1 \\
\hline 19 & $\begin{array}{l}\text { Opportunity to interact with other } \\
\text { disciplines }\end{array}$ & 4.2 & 4.2 & 0 \\
\hline 17 & $\begin{array}{l}\text { Opportunities for social contact with } \\
\text { colleagues at work }\end{array}$ & 4.0 & 4.0 & 0 \\
\hline 20 & $\begin{array}{c}\text { Opportunities to interact with } \\
\text { universities/academics }\end{array}$ & 3.5 & 3.5 & 0 \\
\hline 28 & Opportunities to write/publish & 3.7 & 3.6 & 0.1 \\
\hline 8 & Number of weekends off per month & 4.5 & 4.4 & 0.1 \\
\hline 7 & Opportunity/option to work part-time & 4.0 & 3.7 & 0.3 \\
\hline 21 & $\begin{array}{l}\text { Opportunities to belong to ICU } \\
\text { committees }\end{array}$ & 3.8 & 3.4 & 0.4 \\
\hline 6 & $\begin{array}{l}\text { Opportunity to work normal business } \\
\text { hours (non-shifts) }\end{array}$ & 4.8 & 4.3 & 0.5 \\
\hline 18 & $\begin{array}{l}\text { Opportunities for social contact with } \\
\text { colleagues outside work }\end{array}$ & 3.8 & 3.2 & 0.6 \\
\hline 11 & Option for maternity/paternity leave & 4.1 & 3.4 & 0.7 \\
\hline
\end{tabular}


Table 4. High/low satisfaction versus high/low importance

\begin{tabular}{|c|c|c|}
\hline \multirow{2}{*}{ Satisfaction } & \multicolumn{2}{|c|}{ Importance } \\
\hline & Low $<3.5$ & High $\geq 4.0$ \\
\hline High $\geq 4.0$ & Maternity/paternity leave & $\begin{array}{l}\text { Working normal business hours } \\
\text { Number of weekends off per month } \\
\text { Flexibility of days of work } \\
\text { Control over work } \\
\text { Level of responsibility } \\
\text { Immediate supervisor } \\
\text { Control over work conditions } \\
\text { Interaction with other disciplines } \\
\text { ICU medical researchers } \\
\text { Working with other RCs } \\
\text { Input into decision making } \\
\text { Social contact at work }\end{array}$ \\
\hline Low $<3.5$ & Child care facilities & $\begin{array}{l}\text { Compensation for weekend work } \\
\text { Salary Level } \\
\text { Recognition by management } \\
\text { Career advancement } \\
\text { Research processes } \\
\text { Encouragement, feedback } \\
\text { Number of hours worked } \\
\text { Remuneration package } \\
\text { Recognition by ICU clinical staff }\end{array}$ \\
\hline
\end{tabular}


Table 5. Factor Analysis for MMIS

\begin{tabular}{|c|c|c|c|c|c|c|c|c|c|c|c|}
\hline \multirow[b]{2}{*}{ Importance - Items } & \multicolumn{11}{|c|}{ Factor } \\
\hline & 1 & 2 & 3 & 4 & 5 & 6 & 7 & 8 & 9 & 10 & 11 \\
\hline \multicolumn{12}{|l|}{ Professional Opportunities } \\
\hline \multirow{6}{*}{\multicolumn{12}{|c|}{ Praise/Recognition }} \\
\hline & & & & & & & & & & & \\
\hline & & & & & & & & & & & \\
\hline & & & & & & & & & & & \\
\hline & & & & & & & & & & & \\
\hline & & & & & & & & & & & \\
\hline Having work recognised by clinical staff & 0.23 & 0.84 & -0.03 & 0.05 & -0.04 & 0.05 & 0.02 & 0.10 & 0.23 & 0.17 & 0.10 \\
\hline Receiving encouragement \& positive feedback & -0.03 & 0.82 & 0.15 & 0.03 & 0.01 & 0.28 & -0.04 & -0.13 & 0.00 & -0.10 & -0.03 \\
\hline Having work recognised by ICU management & 0.25 & 0.60 & 0.03 & 0.21 & -0.01 & -0.12 & 0.17 & 0.21 & -0.11 & 0.16 & 0.16 \\
\hline \multicolumn{12}{|l|}{ Work/Life Balance } \\
\hline Flexibility of weekends off (without on-call) & -0.07 & 0.00 & 0.91 & 0.02 & -0.05 & -0.10 & 0.12 & 0.02 & -0.03 & 0.02 & 0.02 \\
\hline Number of weekends off per month & -0.10 & 0.16 & 0.79 & 0.00 & 0.02 & 0.31 & -0.10 & -0.04 & 0.01 & 0.14 & 0.09 \\
\hline $\begin{array}{l}\text { The number of hours worked } \\
\text { Family/Work Balance }\end{array}$ & 0.12 & -0.28 & 0.41 & 0.36 & 0.17 & -0.03 & -0.01 & -0.15 & 0.37 & 0.18 & 0.36 \\
\hline Availability of maternity/paternity leave & -0.02 & 0.08 & 0.00 & 0.94 & 0.06 & 0.00 & 0.04 & 0.00 & 0.04 & -0.05 & 0.05 \\
\hline $\begin{array}{l}\text { Convenient childcare facilities available } \\
\text { Extrinsic Rewards }\end{array}$ & -0.05 & 0.08 & 0.04 & 0.91 & 0.04 & 0.04 & -0.01 & 0.06 & 0.11 & 0.01 & 0.02 \\
\hline Annual leave entitlements & -0.12 & 0.15 & 0.03 & 0.12 & 0.78 & 0.10 & 0.34 & -0.08 & -0.05 & 0.06 & 0.03 \\
\hline Non-salary aspects of remuneration package & 0.02 & -0.25 & -0.46 & -0.01 & 0.63 & -0.20 & 0.09 & -0.01 & 0.23 & 0.15 & 0.19 \\
\hline Salary level & 0.01 & -0.01 & 0.05 & 0.28 & 0.62 & -0.12 & -0.03 & 0.02 & 0.13 & -0.36 & 0.28 \\
\hline $\begin{array}{l}\text { Work relationship with other ICU research staff } \\
\text { Interaction }\end{array}$ & -0.22 & 0.22 & -0.05 & 0.21 & -0.55 & 0.05 & 0.31 & 0.03 & 0.11 & 0.05 & 0.41 \\
\hline Social contact with colleagues outside work & 0.19 & -0.04 & -0.05 & 0.14 & -0.21 & 0.74 & 0.34 & 0.02 & 0.08 & 0.16 & 0.08 \\
\hline Social contact with colleagues at work & 0.13 & 0.28 & 0.23 & -0.05 & 0.06 & 0.73 & -0.01 & 0.04 & -0.13 & 0.16 & -0.09 \\
\hline Interaction with other disciplines & 0.23 & 0.38 & -0.42 & -0.09 & 0.40 & 0.43 & -0.05 & 0.09 & 0.05 & -0.16 & 0.07 \\
\hline \multicolumn{12}{|l|}{ Research Departm } \\
\hline $\begin{array}{l}\text { Working relationship with ICU medical staff } \\
\text { who act as PIs, Cls or research director }\end{array}$ & 0.15 & -0.01 & -0.10 & -0.03 & 0.20 & -0.07 & 0.79 & -0.07 & 0.20 & 0.01 & -0.08 \\
\hline What the research processes in the unit are & 0.09 & 0.05 & 0.20 & -0.09 & -0.12 & 0.37 & 0.67 & 0.15 & 0.02 & -0.17 & 0.24 \\
\hline \multicolumn{9}{|l|}{ Control/Responsibility } & & & 0.00 \\
\hline Having responsibility at work & 0.20 & 0.28 & 0.10 & -0.05 & -0.21 & -0.14 & 0.17 & 0.76 & 0.08 & 0.06 & -0.22 \\
\hline Having control over work & -0.04 & -0.17 & 0.08 & 0.08 & 0.24 & 0.31 & -0.01 & 0.72 & -0.19 & 0.06 & -0.06 \\
\hline $\begin{array}{l}\text { Having input into decision making at work } \\
\text { Flexibility Days/Hours }\end{array}$ & 0.18 & 0.06 & -0.27 & 0.02 & -0.11 & -0.02 & -0.08 & 0.67 & -0.02 & 0.00 & 0.34 \\
\hline Flexibility of days of work & -0.07 & 0.16 & -0.02 & 0.09 & 0.04 & -0.07 & 0.08 & -0.02 & 0.84 & -0.08 & 0.16 \\
\hline $\begin{array}{l}\text { Having the option to work part-time } \\
\text { Control/Conditions }\end{array}$ & -0.01 & 0.00 & -0.02 & 0.31 & 0.09 & 0.20 & 0.06 & -0.11 & 0.59 & 0.45 & -0.14 \\
\hline Having control over working conditions & 0.08 & 0.23 & -0.01 & 0.01 & -0.15 & -0.03 & -0.05 & 0.28 & -0.06 & 0.73 & -0.03 \\
\hline Work normal business hours (Non-shifts) & -0.09 & -0.10 & 0.28 & -0.10 & 0.09 & 0.27 & 0.02 & -0.15 & 0.08 & 0.71 & 0.15 \\
\hline \multicolumn{12}{|l|}{ Compensation-Weekends } \\
\hline Being compensated to work on weekends & 0.15 & 0.10 & 0.08 & 0.03 & 0.13 & 0.01 & 0.02 & 0.00 & 0.08 & 0.02 & 0.86 \\
\hline Cronbach's Alpha & 0.85 & 0.75 & 0.68 & 0.94 & 0.25 & 0.58 & 0.59 & 0.61 & 0.54 & 0.36 & $\mathrm{n} / \mathrm{a}$ \\
\hline Alpha if item & & & $0.79^{\mathrm{a}}$ & & $0.64^{\mathrm{b}}$ & $0.67^{\mathrm{c}}$ & & & & & \\
\hline Eigenvalue & 4.63 & 3.24 & 3.04 & 2.20 & 1.91 & 1.87 & 1.73 & 1.59 & 1.42 & 1.20 & 1.12 \\
\hline$\%$ Variance explained & 14.95 & 10.46 & 9.81 & 7.11 & 6.17 & 6.03 & 5.59 & 5.14 & 4.59 & 3.86 & 3.61 \\
\hline
\end{tabular}

a If 'the number of hours worked' deleted

b If 'work relationship with other ICU research staff' deleted

c If 'interaction with other disciplines' deleted' 
Figure 1. Scree Plot of MMIS Items

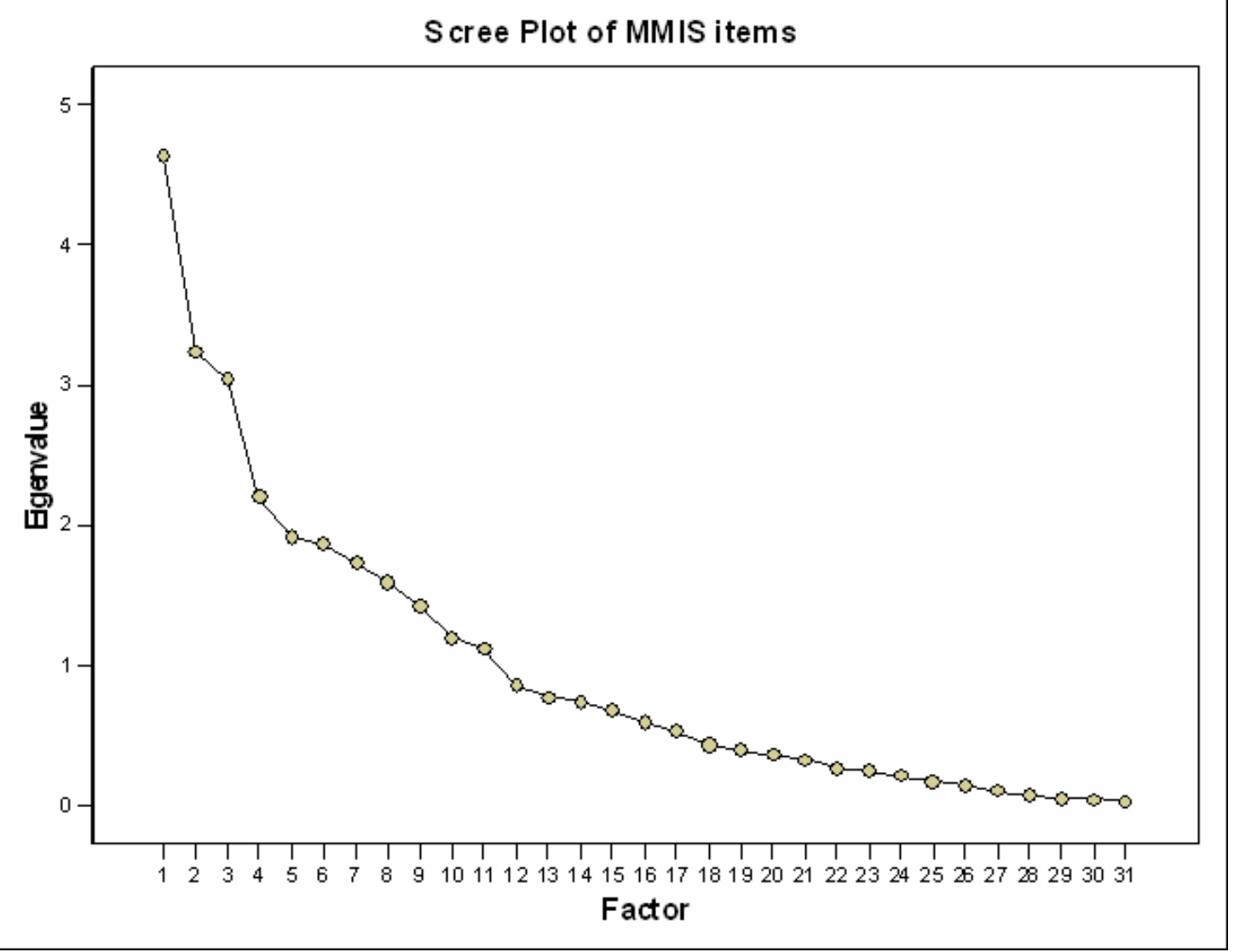

